\title{
Influência do resíduo de PVC como agregado no concreto para peças de pavimentos intertravados
}

\author{
Influence of PVC waste as aggregate in the concrete of \\ interlocking block pavement
}

\begin{abstract}
Adriana Goulart Santos Ana Karoliny Ferrari

\section{Resumo}

${ }^{1}$ Adriana Goulart Santos ${ }^{1}$ Universidade do Estado de Santa Catarina J oinville - SC - Brasil

${ }^{2}$ Ana Karoliny Ferrari ${ }^{2}$ Arquiteta J oinville - SC - Brasil

Recebido em 22/12/17 Aceito em 29/09/18

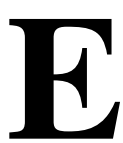

ste trabalho apresenta uma análise da influência do resíduo de PVC como substituto parcial do agregado miúdo em propriedades físicas como absorção de água, índice de vazios, massa específica e de resistência à compressão do concreto dosado para peças de pavimentos intertravados. Foram analisados quatro traços de concreto, sendo um de referência, apenas com agregados naturais, e outros três com substituição de 5\%, 10\% e 15\% de resíduo de PVC. Verificou-se que, estatisticamente, o resíduo de PVC influenciou na redução da resistência à compressão e da massa específica das peças. Em relação à absorção de água e ao índice de vazios, o resíduo de PVC não influenciou nos resultados desses ensaios. Quanto ao ensaio de durabilidade por secagem e molhagem, pode-se observar aumento da perda de massa com o aumento da porcentagem de PVC no traço. A análise microscópica dos traços possibilitou observar a forma dos grãos dos resíduos de PVC e sua interação com os demais materiais constituintes do concreto na interpretação dos resultados dos ensaios. A análise dos resultados mostrou que o resíduo de PVC pode ser incorporado ao concreto de peças para pavimentos sem que estas sofram significativas alterações em suas propriedades.

Palavras-chave: Resíduo de PVC. Peças de concreto. Pavimento.

\section{Abstract}

This study presents an analysis of the influence of PVC waste as a partial substitute of fine natural aggregate on physical properties such as water absorption, voids index, specific mass and the compressive strength of interlocking block pavements. Four concrete mixtures were analysed: a reference mixture with $0 \%$ replacement, and mixtures with 5\%, 10\% and 15\% of fine aggregate made of PVC waste. The study showed that, statistically, the $P V C$ waste influenced the decrease of the compressive strength and the specific mass of the blocks. The PVC waste proved to have no influence on the test results for water absorption and the voids index. The durability test for drying and wetting showed that there was an increase in the loss of mass with the increase of the percentage of PVC in the concrete mixture. The microscopic analysis of the concrete mixtures allowed observation of the shape of the grains of the PVC residues and their interaction with the other constituent materials of the concrete, aiding in the interpretation of the test results. Hence, the results showed that PVC waste may be incorporated into concrete blocks without causing significant alterations in their properties.

Keywords: PVC-waste. Concrete blocks. Pavement.
\end{abstract}




\section{Introdução}

Os temas sustentabilidade e construção civil são claramente interdependentes na atualidade. A preocupação com o meio ambiente e com os resíduos gerados por todo tipo de indústria tem sido crescente. Um dos maiores desafios da sociedade moderna consiste no equilíbrio no consumo e exploração de recursos naturais e, também, na geração excessiva e disposição final dos resíduos sólidos. O desenvolvimento sustentável é o ápice do equilíbrio entre o homem, a natureza e a economia, de forma que a geração atual possa usufruir o meio ambiente sem comprometer as gerações futuras (COSTA; IGNÁCIO, 2011). Em 2010 foi promulgada a Política Nacional de Resíduos Sólidos, que tem como principal objetivo difundir uma visão moderna que contribua para o desenvolvimento de soluções viáveis e eficientes para o problema dos resíduos sólidos urbanos. A Política Nacional defende a ideia de uma responsabilidade compartilhada entre governo, empresas e população, incentiva a reinserção dos resíduos no ciclo produtivo e regulamenta os planos de gerenciamento do lixo (LOMASO et al., 2015). A legislação brasileira determina que resíduos sólidos gerados pela indústria sejam dispostos em aterros controlados, os quais, muitas vezes, atingem sua capacidade máxima em alguns anos. Por isso há, mais que uma preocupação, a necessidade de reinserção de produtos no ciclo de produção de que saíram ou em ciclos de outros setores. A gestão e a disposição inadequada dos resíduos sólidos causam impactos socioambientais, muitas vezes irreversíveis. Segundo a Associação Brasileira de Limpeza Pública e Resíduos Especiais (ABRELPE, 2016), a geração total de resíduos sólidos no Brasil em 2015 foi de 79,9 milhões de toneladas, o que representou um aumento de cerca de $1,7 \%$ na quantidade de resíduos quando comparado ao ano anterior.

Com relação à construção civil, pode ser considerado um dos setores que mais geram tais resíduos, tendo grande influência no montante final produzido nos centros urbanos (SILVA; FERNANDES, 2012). Ainda avaliando a sustentabilidade e a construção civil, pode-se destacar outro impacto ambiental: a escassez dos recursos naturais. Um estudo realizado pelo Sindicato da Indústria da Construção Civil no Estado de São Paulo (Sinduscon-SP) indicou que a indústria da construção é uma das que mais utilizam recursos naturais, desde a extração e produção de insumos até a execução e operação das edificações. Até $75 \%$ do que é utilizado vem do meio natural (AGOPYAN; JOHN, 2011). O concreto, por exemplo, é o segundo material mais consumido do mundo, superado apenas pela água (CHEN et al.,
2010). A areia é largamente utilizada no setor da construção civil, sendo retirada do solo pela mineração, o que causa impactos ambientais. A melhor maneira de diminuir a utilização desses recursos e conservar o meio ambiente é o emprego de materiais reciclados ou alternativos (ALWAELI, 2013). Sendo assim, a reciclagem e a recuperação dos recursos são de grande importância e podem ser incluídas como práticas comuns, uma alternativa que visa à sustentabilidade, pois é a melhor maneira de solucionar os problemas dos resíduos e de eliminá-los, especialmente melhorando as técnicas de reutilização, fundamental para a preservação dos recursos naturais (DUTTA; DAS, 2010).

Entre os resíduos sólidos gerados na construção civil em geral, pode-se citar o policloreto de vinila, conhecido pela sigla PVC. O PVC é o mais versátil entre os plásticos. Devido à necessidade de sua resina ser formulada mediante a incorporação de aditivos, o PVC pode ter suas características alteradas dentro de um amplo campo de funções, desde algum produto rígido até algo extremamente flexível. O material pode ser moído, injetado, moldado, extrudado, entre outros (RODOLFO JUNIOR; NUNES; ORMANJI, 2006). O PVC representa $4,7 \%$ do total de plásticos e cerca de $0,7 \%$ do resíduo total gerado no Brasil (INSTITUTO..., 2013).

O segmento da construção civil é responsável pelo consumo de mais de $60 \%$ do PVC fabricado no Brasil (LIMA; ROCHA; KONAGNO, 2012), por isso a relevância desse material no setor. Para se ter uma ideia melhor, segundo um estudo encomendado pelo Instituto do PVC (2013), o índice de reciclagem de PVC pós-consumo do material foi de apenas 19\% em 2011. A reciclagem mais indicada para o PVC, quando há homogeneidade no material, é a mecânica. Possui baixa produção de poluição e grande aceitação em âmbito mundial, porém depende de programas de incentivo de coleta seletiva da sociedade (SADATSHOJAI; BAKHSHANDEH, 2010). Sendo assim, esse setor de reciclagem tem um grande potencial, ainda pode se desenvolver muito.

O aperfeiçoamento dos métodos e a aplicação de medidas racionais podem contribuir para aumentar a eficácia de produção na construção civil, e é dentro desse contexto que atualmente a utilização de peças pré-moldadas de concreto vem ganhando muito espaço nos canteiros de obras do país. Concomitantemente, a utilização de pavimentos com peças pré-moldadas também está crescendo. Sobre esses materiais cimentícios, já existem estudos que mostram a possibilidade de se utilizarem materiais reciclados de forma prática, 
viável e ambientalmente sustentável, como os de Amaral et al. (2013), que utilizaram areia de fundição, Carvalho (2013), que utilizou retífica de cerâmica, e Ferreira et al. (2016), resíduos de postes de concreto.

Diante do exposto, a utilização de PVC reciclado como agregado miúdo em peças de concreto pode ser uma nova destinação de descarte para esse material, reduzindo também o consumo de agregados naturais. Assim, o objetivo geral deste trabalho é avaliar a influência do resíduo de PVC como substituto parcial do agregado miúdo natural em propriedades físicas como absorção de água, índice de vazios, massa específica, durabilidade e resistência mecânica à compressão axial do concreto dosado para peças de pavimentos intertravados.

\section{Programa experimental}

As propriedades analisadas no programa experimental da pesquisa foram definidas a partir das características necessárias e exigidas pelas normas brasileiras para o emprego de peças de concreto em pavimentos intertravados. Desse modo, tendo como premissa a avaliação de desempenho do concreto, definiram-se as seguintes propriedades a serem avaliadas, consideradas como as respostas da pesquisa:

(a) resistência à compressão axial;

(b) absorção de água;

(c) índice de vazios;

(d) massa específica;

(e) durabilidade por molhagem e secagem; e

(f) análise da matriz cimentícia através de microscopia.

Por conseguinte, foram definidos os seguintes fatores controláveis:

(a) substituição parcial do agregado miúdo por resíduo PVC nas porcentagens de 0\%, 5\%, 10\% e $15 \%$ no traço do concreto;

(b) idade de ensaio de resistência à compressão, de absorção de água, índice de vazios e massa específica igual a 28 dias de idade de cura; e

(c) idade de ensaio de durabilidade de acordo com a norma específica.

As porcentagens de substituição do agregado miúdo foram escolhidas com base em trabalhos científicos que substituíram esse agregado por agregado reciclado, como o de Kou et al. (2009).

\section{Materiais}

Os materiais utilizados nesta pesquisa foram cimento CP V ARI, com massa específica de 3,01 $\mathrm{g} / \mathrm{cm}^{3}$, agregado miúdo natural em duas granulometrias distintas (areias do tipo 1 e 2), água proveniente da rede de abastecimento público e agregado graúdo formado de pedrisco, obtido artificialmente por britagem de rochas da região nordeste do estado de Santa Catarina.

O PVC foi obtido a partir de eletroduto corrugado reforçado descartado de uma obra de construção civil. O resíduo de PVC foi moído em um moinho de facas do Laboratório de Processamento de Polímeros da Universidade do Estado de Santa Catarina (Udesc). O aspecto visual do resíduo de PVC, após esse procedimento, é apresentado na Figura 1.

\section{Ensaios de caracterização física dos agregados}

Os ensaios de caracterização física realizados nos agregados miúdos naturais (areia do tipo 1 e areia do tipo 2) e no resíduo de PVC foram composição granulométrica, dimensão máxima característica (DMC) e módulo de finura, seguindo a NBR NM 248 (ABNT, 2003), e massa específica do agregado, seguindo a NBR NM 52 (ABNT, 2009a). O PVC, antes dos ensaios de caracterização física, passou por uma peneira com abertura de $4,75 \mathrm{~mm}$. A determinação da massa específica do agregado graúdo seguiu as prescrições da NBR NM 53 (ABNT, 2009b). A Tabela 1 apresenta os resultados dos ensaios de caracterização física dos agregados.

A partir dos valores do módulo de finura das areias foi possível classificar a areia do tipo 1 como fina, e a do tipo 2 como média. Analisando os valores de dimensão característica máxima dos agregados foi possível seguir o recomendado por Gregorio (2012). Esse autor recomendou em seu relatório técnico utilizar um diâmetro máximo de agregado de 6,3 $\mathrm{mm}$ em peças de concreto, de forma a garantir o bom acabamento superficial.

\section{Dosagem do concreto seco}

A definição do traço de concreto utilizado nesta pesquisa teve como ponto de partida aquele determinado no estudo de Amadei (2011). A autora avaliou 15 diferentes traços, levando em consideração o diagrama do Instituto de Pesquisas Tecnológicas (IPT), adaptado para concretos secos e obedecendo à relação da resistência à compressão e de massa específica. O traço é da ordem 1:4, com fator água-cimento de 0,32 e teor de umidade de $6,4 \%$. 
Figura 1 - Resíduo de PVC após o procedimento de moagem

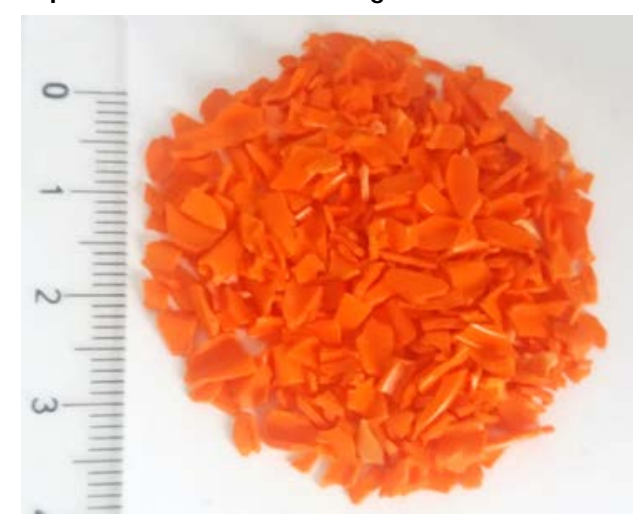

Tabela 1 - Caracterização física dos agregados

\begin{tabular}{c|c|c|c}
\hline Agregados & $\begin{array}{c}\text { Dimensão característica } \\
\text { máxima }(\mathbf{m m})\end{array}$ & Módulo de finura & $\begin{array}{c}\text { Massa específica } \\
\mathbf{( g / \mathbf { c m } ^ { 3 } )}\end{array}$ \\
\hline Areia - tipo 1 & 1,18 & 1,31 & 2,67 \\
Areia - tipo 2 & 2,36 & 2,66 & 2,60 \\
Agregado graúdo & 4,75 & 3,07 & 2,60 \\
Resíduo de PVC & 2,36 & 4,27 & 0,55 \\
\hline
\end{tabular}

Com esse traço foram ajustadas as proporções dos materiais, o fator água-cimento e a consistência do concreto às características físicas dos materiais utilizados nesta pesquisa. A proporção entre a areia fina e a areia média foi ajustada a partir do método do menor volume de vazios. Desse modo, encontrou-se a proporção de $43 \%$ de areia fina e de $57 \%$ de areia média para agregado miúdo. Em seguida, encontraram-se $67 \%$ de agregado miúdo e $33 \%$ de pedrisco. O aditivo foi dosado conforme indicação do fabricante.

Segundo Buttler (2007), a umidade alcançada em concreto seco deve estar compreendida entre $6 \%$ e $8 \%$, já que é diferente de concretos plásticos. Nos plásticos, os vazios são ocupados pela pasta de cimento e água, e em concreto secos, a presença dos vazios é retirada durante a vibrocompactação, no procedimento de moldagem das peças. Para que o traço avaliado fosse considerado ideal quanto à consistência e trabalhabilidade, e como não existe um teste específico para concreto seco, foi utilizado o método empírico sugerido por Hood (2006): o método do ponto de pelota. Esse método tem por objetivo definir o ponto ideal de água na mistura. Sendo assim, a umidade dos traços de concreto manteve-se constante com um valor percentual de 6,9\%. A Tabela 2 apresenta o traço de referência definido para essa pesquisa após os referidos ajustes ao traço de Amadei (2011).

Para a definição dos traços com 5\%, 10\% e 15\% de substituição da areia por resíduo de PVC, as proporções de cimento, areia fina e pedrisco foram mantidas. O resíduo de PVC apresentou o diâmetro máximo característico semelhante à areia do tipo 2 , como pode ser observado na Tabela 1. Por isso, optou-se por substituí-lo no traço de concreto. A substituição da areia média por resíduo de PVC foi feita em volume. Para a moldagem das peças, o traço apresentado em volume foi transformado em massa. Os traços com $0 \%, 5 \%, 10 \%$ e $15 \%$ de substituição de resíduo foram denominados respectivamente de PVC0, PVC5, PVC10 e PVC15.

\section{Moldagem das peças de concreto}

O formato das peças moldadas é retangular do tipo I, conforme prescrição da NBR 9781 (ABNT, 2013). A moldagem das peças para pavimento intertravado foi realizada com uma vibroprensa automática por comando hidráulico, cedida por uma empresa comercial. O equipamento também possuía um sensor de umidade integrado, utilizado para se estabelecer o teor de umidade adequado de cada mistura.

\section{Estudo das propriedades físicas e de resistência à compressão do concreto no estado endurecido}

Para o ensaio de resistência à compressão foram utilizadas 6 peças para a idade de 28 dias, quantidade mínima permitida pela NBR 9781 (ABNT, 2013). Outras 3 peças foram utilizadas para o ensaio de absorção de água, 3 peças para determinação de índice de vazios e massa específica e, por fim, 3 peças para o ensaio de durabilidade. $\mathrm{O}$ valor de 3 peças para esses ensaios é superior ao 
limite mínimo das normas, que costumam exigir apenas 1 ou 2 peças. Para o ensaio de microscopia, foram utilizados fragmentos de peças originadas após o ensaio de resistência à compressão axial.

O ensaio de resistência à compressão foi executado seguindo a NBR 9781 (ABNT, 2013), até a ruptura completa das peças.

A determinação da absorção de água das peças foi realizada de acordo com as prescrições da NBR 9781 (ABNT, 2013). Já a determinação do índice de vazios e da massa específica seguiu as prescrições da NBR 9778 (ABNT, 2009c). A determinação da durabilidade das peças foi feita pelo método de molhagem e secagem, seguindo os procedimentos descritos na NBR 13554 (ABNT, 2012).

\section{Análise estatística}

Para a análise estatística foi utilizado o software $\mathrm{R}$ Studio, e o nível de confiança adotado foi de 95\%. Com a ferramenta de teste de hipóteses e de análise de variância sem repetição, também conhecida como ANOVA, foi possível analisar a interferência do resíduo e verificar se houve ou não significância estatística nos resultados de cada experimento. Quando a ANOVA mostra que existem diferenças significativas entre as médias dos tratamentos, é necessário aplicar o teste de Tukey, utilizado para verificar quais médias são estatisticamente diferentes entre si ao nível de 5\% de probabilidade. Essas análises tiveram por objetivo avaliar estatisticamente se existe alguma diferença significativa na variação da porcentagem de substituição de resíduo de PVC nas propriedades de respostas, definidas no programa experimental do estudo. As propriedades de resposta analisadas que tiveram a ANOVA calculada foram resistência à compressão axial, absorção de água, índice de vazios e massa específica das peças de concreto.

\section{Análise microestrutural por Microscópio Eletrônico de Varredura (MEV)}

A análise microestrutural foi realizada no Laboratório de Caracterização de Materiais do Departamento de Engenharia Mecânica da Udesc. $\mathrm{O}$ equipamento utilizado foi o microscópio eletrônico de varredura (MEV). Essa análise possibilitou observar a forma dos grãos dos resíduos de PVC e sua interação com os demais materiais constituintes do concreto. Para esse procedimento foram preparadas amostras de cada traço de concreto avaliado no estudo (PVC0, PVC5, PVC10 e PVC15).

\section{Resultados e discussão \\ Resistência à compressão axial estimada}

A Figura 2 apresenta os valores médios de resistências à compressão estimadas aos 28 dias de idade de cura e os respectivos desvios padrão de cada traço avaliado.

Tabela 2 - Traço de referência

\begin{tabular}{c|c|c|c|c|c}
\hline Traço & Cimento & Areia fina & Areia média & Pedrisco & $\mathbf{a} / \mathbf{c}$ \\
\hline Proporção em volume & 1,00 & 1,05 & 1,39 & 1,18 & 0,35 \\
\hline
\end{tabular}

Figura 2 - Valores médios das resistências estimadas à compressão aos 28 dias e desvios padrão de cada traço avaliado

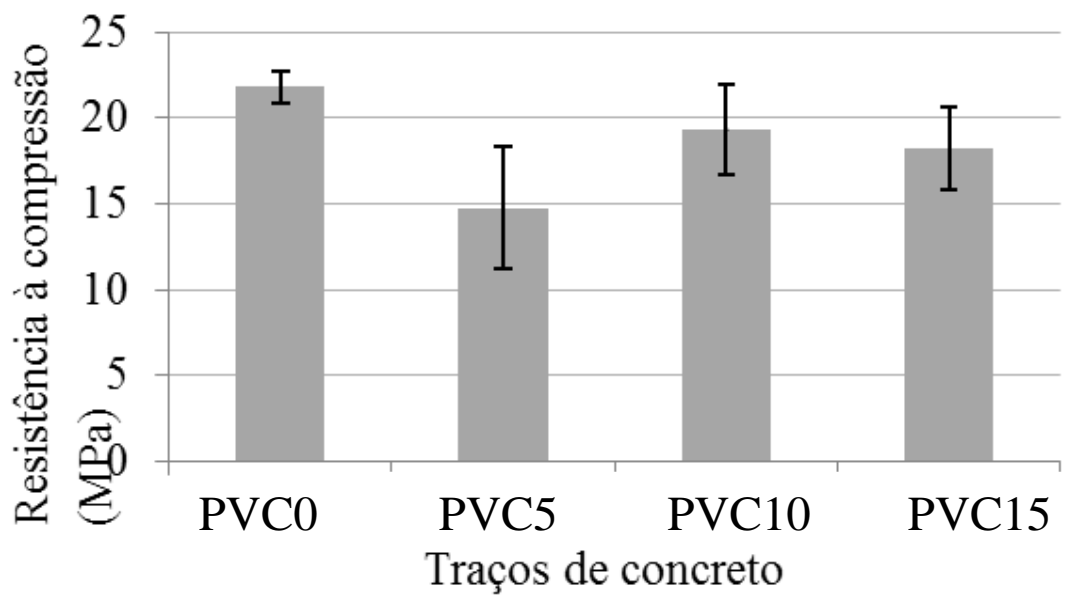


Analisando o gráfico da Figura 1, pode-se observar que as médias de resistência à compressão estimadas de cada traço ficaram abaixo do limite mínimo exigido por norma, ou seja, $35 \mathrm{MPa}$ para o tráfego leve de veículos comerciais. Entretanto, é importante ressaltar que a norma brasileira poderia ser revisada. Se comparada com as normas internacionais de países como Austrália e África do Sul, os quais se encontram em regiões de condições climáticas semelhantes às do Brasil, seria pertinente aceitar recomendações semelhantes às utilizadas nesses países. Nas normas da Austrália e da África do Sul, a resistência característica à compressão exigida é de $25 \mathrm{MPa}$ para tráfego leve e de $35 \mathrm{MPa}$ para os demais tipos de tráfego. Já para o calçamento de praças e ciclovias, os valores de 15 MPa são considerados suficientes para a magnitude desse tipo de solicitação (BITTENCOURT, 2012). Adebola et al. (2017), na Nigéria, também observaram diminuição na resistência à compressão nas peças de concreto quando se aumentou a porcentagem de substituição de agregado natural por polietileno reciclado e sugeriram que sejam utilizados na pavimentação de calçadas.

Além disso, um estudo realizado pela Confederação Nacional do Transporte (CNT) mostra que a metodologia utilizada para dimensionar pavimentos no Brasil tem uma defasagem de 40 anos em relação a outros países. Em Portugal, por exemplo, país do tamanho do estado do Pernambuco, existe uma divisão territorial em três zonas que levam em consideração as variações climáticas para o dimensionamento dos pavimentos, além do emprego de materiais utilizados na pavimentação (CONFEDERAÇÃO..., 2017).

Ainda analisando o gráfico da Figura 2, pode-se observar que o traço PVC10, ou seja, com $10 \%$ de substituição do resíduo de PVC, obteve a maior resistência à compressão quando comparado aos demais traços que continham o resíduo de PVC. Esse fato corrobora as observações de Sharma e Bansal (2016), que afirmam que os materiais poliméricos tendem a diminuir a resistência à compressão do concreto. Já o estudo de Rahmani et al. (2013) concluiu que a resistência à compressão do concreto dosado com $10 \%$ de substituição de partículas de plástico pela areia foi mais próxima daquela obtida com o concreto dosado somente com agregados naturais.

Pela análise de variância, conforme os dados apresentados na Tabela 3, o valor-p (probabilidade de significância) foi de 0,0011 , ou seja, inferior ao nível de significância $(\alpha)$, igual a 0,05 , definido previamente. Cabe salientar que o valor-p indica se a hipótese de igualdade entre os resultados referentes à variação do teor de PVC na propriedade avaliada deve ser aceita ou rejeitada. Se o valor-p for superior ao nível de significância, deve-se aceitar; caso contrário, deve-se rejeitar a igualdade.

Outra forma de se verificar se há ou não a igualdade é comparar o valor de F com F crítico: o F crítico limita a região de rejeição e significa que, para valores de $\mathrm{F}$ superiores, a hipótese da igualdade deve ser rejeitada. Nesse caso, o índice F crítico foi inferior ao valor F. Sendo assim, pode-se concluir que a presença do PVC influenciou na diminuição de resistência à compressão.

Pelo teste de Tukey, verificou-se que as diferenças são significativas (p-valor menor que 0,05 ) entre os traços PVC0 e PVC5 e também entre os traços PVC5 e PVC10.

\section{Absorção de água}

Para Hood (2006), a absorção de água das peças de concreto é uma propriedade para estimar sua durabilidade. Quanto maior o percentual de absorção, menor a durabilidade e maior o ataque químico devido aos elementos químicos. A média do percentual de absorção de água dos traços avaliados ficou entre 3,50\% e 4,52\%, valores dentro do limite exigido por norma, de $6 \%$. Os valores médios de absorção de água de cada traço avaliado e os desvios padrão são apresentados em forma gráfica na Figura 3.

Pela análise de variância, demonstrada na Tabela 4, o valor-p foi de 0,0671 , ou seja, superior ao nível de significância $(\alpha)$. Analisando o índice F crítico, verifica-se que foi superior ao valor F. Desse modo, pode-se constatar que a presença do PVC não influenciou na absorção de água das peças de concreto ensaiadas.

Tabela 3 - Análise de variância dos resultados do ensaio de resistência à compressão axial

\begin{tabular}{c|c|c|c|c|c|c}
\hline Fonte de variação & SQ & Gl & MQ & F & Valor-p & F crítico \\
\hline Entre grupos & 153,0681 & 3 & 51,0227 & 7,9567 & 0,0011 & 3,098 \\
Dentro dos grupos & 128,2514 & 20 & 6,4125 & & & \\
Total & 281,3195 & 23 & & & & \\
\hline
\end{tabular}


Figura 3 - Valores médios de absorção de água (em \%) e os desvios padrão de cada traço avaliado

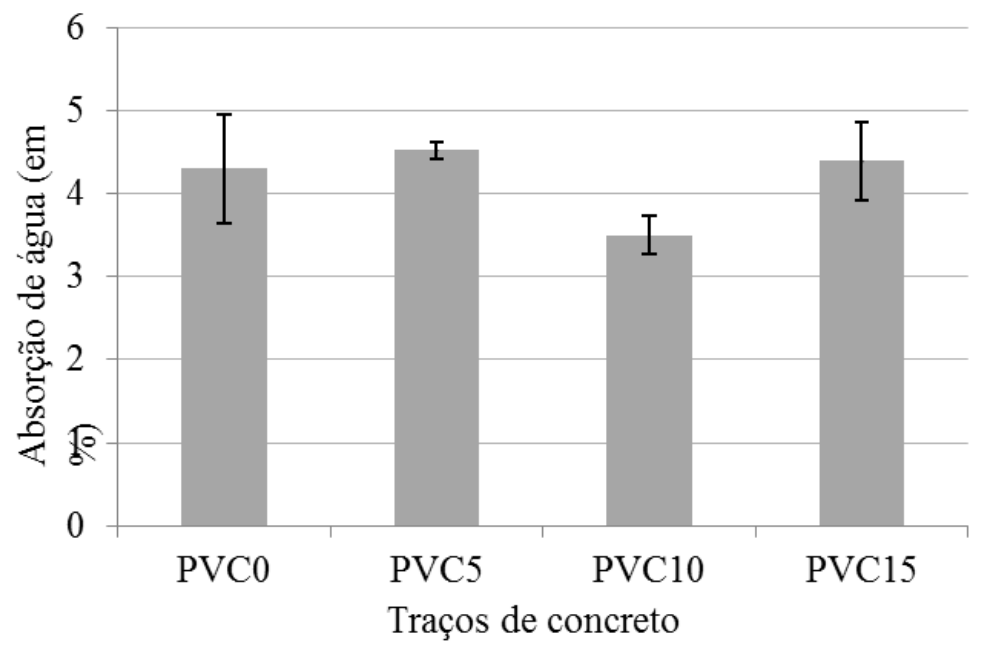

Tabela 4 - Análise de variância dos resultados do ensaio de absorção de água

\begin{tabular}{c|c|c|c|c|c|c}
\hline Fonte de variação & SQ & Gl & MQ & F & Valor-p & F crítico \\
\hline Entre grupos & 1,9010 & 3 & 0,6337 & 3,5568 & 0,0671 & 4,0662 \\
Dentro dos grupos & 1,4253 & 8 & 0,1782 & & & \\
Total & 3,3263 & 11 & & & & \\
\hline
\end{tabular}

O traço PVC5, que obteve a maior média de absorção de água, foi também o que obteve a menor resistência à compressão. Embora estatisticamente não tenha sido comprovada a influência do PVC na absorção de água nas peças, Porrero et al. (2004) afirmam que os resíduos triturados adquirem uma forma relativamente mais alongada e plana, o que promove o surgimento de vazios no concreto e, consequentemente, o aumento na absorção de água.

\section{Índice de vazios}

O gráfico da Figura 4 apresenta a média dos valores dos índices de vazios dos quatro traços avaliados e os respectivos desvios padrão. O índice de vazios dos traços avaliados ficou entre $21,88 \%$ e $25,58 \%$.

$\mathrm{Na}$ análise de variância, conforme dados apresentados na Tabela 5, o valor-p foi de 0,0909, ou seja, superior ao nível de significância $(\alpha)$. O F crítico foi superior ao valor F. Pela análise estatística ressalva-se que o resíduo de PVC não influenciou nos resultados do ensaio.

Observou-se que o índice de vazios aumentou com a adição de resíduos de PVC no concreto. Tal fato pode ser confirmado com o estudo de Rahmani et al. (2013), que constataram que o aumento da porcentagem de resíduos de plásticos na mistura tornou o concreto mais poroso. $\mathrm{O}$ valor da média do índice de vazios do traço PVC15 foi superior aos demais. Todos os traços apresentaram o valor da média do índice de vazios superior a $20 \%$, considerado ideal por Tennis, Leming e Akers (2004), por garantir resistência à compressão adequada e também pela permeabilidade do material.

\section{Massa específica}

Os valores da média de massa específica de cada traço avaliado são apresentados de forma gráfica na Figura 5. Pelo gráfico pode-se observar que as médias de massa específica ficaram entre 2,61\% e 2,74\%.

A Tabela 6 apresenta a análise de variância, em que se pode observar que o valor-p foi de 0,0423 , inferior ao nível de significância. O F crítico foi inferior ao valor F. Pode-se constatar que a presença do PVC influenciou nos resultados deste ensaio.

O traço com menor massa específica, ou seja, o mais leve foi o PVC10, enquanto o traço PVC0 foi o que apresentou a maior massa específica. Através do teste de Tukey verificou-se que as diferenças são significativas (valor-p menor que 0,05 ) entre os traços PVC0 e PVC10 e também entre os traços PVC0 e PVC15. Moura et al. (2018) e Rahmani et al. (2013) também constataram a diminuição da massa específica do concreto quando o agregado miúdo foi substituído por resíduos de plástico, o que ocorre devido ao fato de a massa específica do resíduo de plástico ser menor do que a areia natural. 


\section{Durabilidade por secagem e molhagem}

A Tabela 7 apresenta os resultados do ensaio de durabilidade por secagem e molhagem em peças de concreto de cada traço avaliado. Os valores apresentados na tabela compreendem a porcentagem de volume e de massa (pelo desgaste por escovação) que cada peça perdeu durante os seis ciclos de molhagem e secagem, os quais são exigidos em norma. Para avaliar a perda de volume foi utilizada uma peça, e para avaliar a perda de massa, duas peças.

Figura 4 - Valores médios dos índices de vazios (em \%) e os desvios padrão de cada traço avaliado

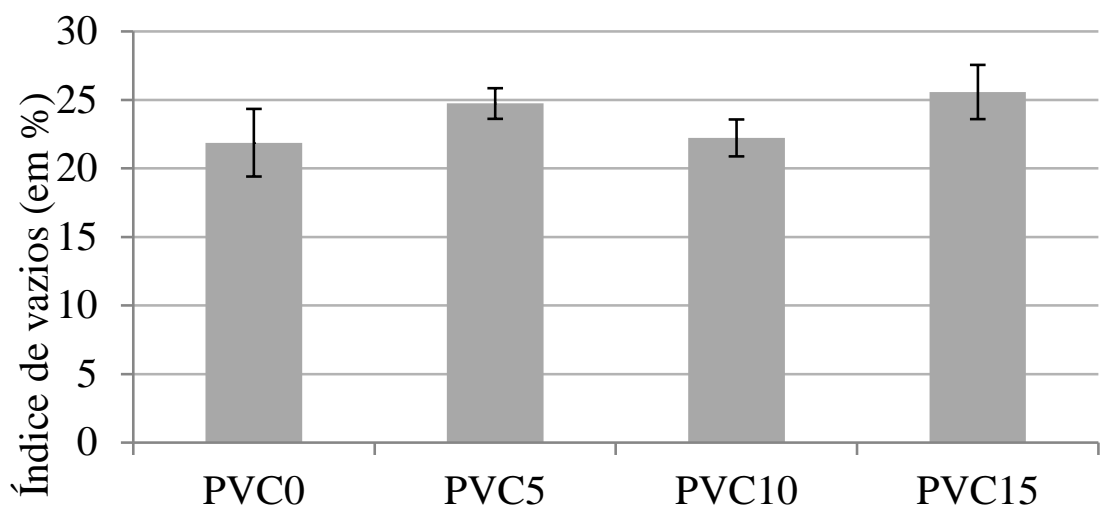

Traços de concreto

Tabela 5 - Análise de variância dos resultados do ensaio de índice de vazios

\begin{tabular}{c|c|c|c|c|c|c}
\hline Fonte de variação & SQ & Gl & MQ & F & Valor-p & F crítico \\
\hline Entre grupos & 30,0962 & 3 & 10,0321 & 3,0687 & 0,0909 & 4,0662 \\
Dentro dos grupos & 26,1533 & 8 & 3,2692 & & & \\
Total & 56,2495 & 11 & & & & \\
\hline
\end{tabular}

Figura 5 - Valores médios da massa específica $\left(\mathrm{em} \mathrm{g} / \mathrm{cm}^{3}\right)$ e os desvios padrão de cada traço avaliado

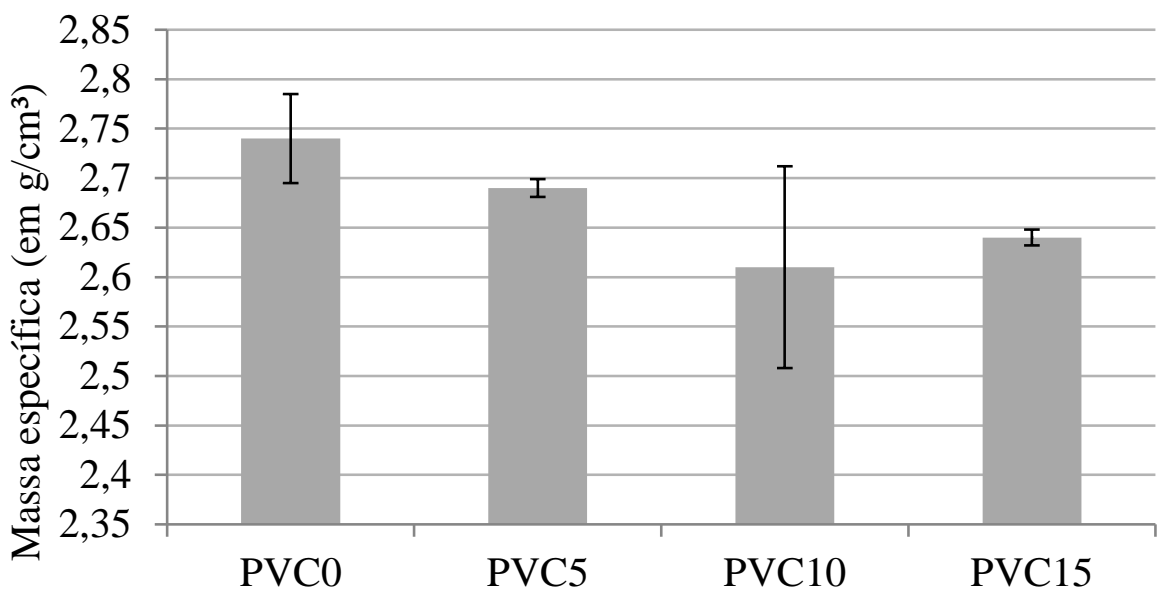

Traços de concreto

Tabela 6 - Análise de variância dos resultados do ensaio de massa específica

\begin{tabular}{c|c|c|c|c|c|c}
\hline Fonte de variação & SQ & Gl & MQ & F & Valor-p & F crítico \\
\hline Entre grupos & 0,0402 & 3 & 0,0134 & 4,3712 & 0,0423 & 4,0662 \\
Dentro dos grupos & 0,0245 & 8 & 0,0031 & & & \\
Total & 0,0647 & 11 & & & & \\
\hline
\end{tabular}


Tabela 7 - Perda de volume e de massa durante os seis ciclos de molhagem e secagem (em \%)

\begin{tabular}{c|c|c|c|c}
\hline Peça & PVC0 & PVC5 & PVC10 & PVC15 \\
\hline Perda de volume & 2,98 & 2,90 & 2,93 & 2,82 \\
\hline \multirow{2}{*}{ Perda de massa } & 3,76 & 3,05 & 3,27 & 3,41 \\
\cline { 2 - 5 } & 3,87 & 3,12 & 3,21 & 3,33 \\
\hline Média da perda de massa & 2,82 & 3,09 & 3,24 & 3,37 \\
\hline
\end{tabular}

Pelos valores apresentados na Tabela 7, pode-se observar que a perda de volume durante o ensaio de molhagem e secagem foi semelhante nos quatro traços avaliados. A maior variação de volume foi entre o traço PVC0 e o PVC15, apresentando 5,5\% de variação, ou seja, o traço que mais perdeu volume foi aquele com maior porcentagem de resíduo de PVC.

Com relação à perda de massa das peças pode-se observar que a média dos valores variou de $2,82 \%$ a 3,37\% entre os quatro traços avaliados. O traço que menos perdeu massa foi o PVC0. Pode-se observar o aumento da perda de massa com o aumento da porcentagem de PVC no traço do concreto.

\section{Análise microestrutural por microscópio eletrônico de varredura}

A Figura 6 apresenta a análise microscópica dos traços de concreto PVC0, PVC5, PVC10 e PVC15 com aproximação de 400 vezes.

Analisando a micrografia do traço PVC0, pode-se constatar que, em alguns pontos, a matriz cimentícia apresentou poros. Os poros estão em maior destaque na matriz cimentícia, e não na interface. Tal ocorrência pode ter sido causada por uma má calibração no sistema de vibrocompactação durante a moldagem das peças. Esse fato pode ser corroborado com a observação do desvio padrão dos valores de resistência à compressão dos traços avaliados, apresentados no gráfico da Figura 2. Tal observação está de acordo com o estudo de Nabeshima, Orsolin e Santos (2011), que afirmaram que um dos fatores que impedem a popularização do pavimento intertravado de concreto é a falta de padronização com relação à qualidade das peças encontradas no mercado.

Também se observou que há poros próximos à interface entre o resíduo de PVC e a matriz cimentícia na micrografia dos traços PVC5, PVC10 e PVC15, como demonstram as Figuras 6b, 6c e 6d. Na Figura 7 pode-se observar a micrografia do traço de concreto PVC10 com aproximação de 2.000 vezes. Nesta figura pode-se observar a interface rugosa do PVC com a matriz cimentícia. Essa interação pode ter melhorado a aderência do PVC à matriz cimentícia e, por isso, ser o traço que obteve a maior resistência à compressão entre os três traços analisados que continham o resíduo de PVC no concreto dosado.

\section{Conclusões}

Neste estudo foi avaliada a influência do resíduo de PVC como substituto parcial do agregado miúdo natural em propriedades físicas como absorção de água, índice de vazios, massa específica, durabilidade e resistência mecânica à compressão axial do concreto dosado para peças de pavimentos intertravados.

Conclui-se que a resistência à compressão estimada de cada traço ficou abaixo do limite mínimo exigido por norma, ou seja, $35 \mathrm{MPa}$, para o tráfego de veículos comerciais. Analisando a micrografia do traço PVC0, pode-se constatar que, em alguns pontos, a matriz cimentícia apresentou poros. Constataram-se também poros próximos à interface entre o resíduo de PVC e a matriz cimentícia na micrografia dos traços PVC5, PVC10 e PVC15. A incidência de poros pode ter sido causada por uma má calibração no sistema de vibrocompactação durante a moldagem das peças, o que levou as peças ensaiadas a não terem obtido maiores ganhos de resistência à compressão, bem como os resultados do referido ensaio terem apresentado elevado desvio padrão.

Comparando as médias de resistência dos traços que continham o resíduo de PVC, o PVC10 obteve a maior resistência à compressão. Analisando a micrografia do traço de concreto PVC10 com aproximação de 2.000 vezes, pode-se observar a interface rugosa do PVC com a matriz cimentícia. Essa interação pode ter melhorado a aderência do PVC à matriz cimentícia e, por isso, ser o traço que obteve a maior resistência à compressão entre os três traços analisados que continham o resíduo de PVC no concreto dosado. Ainda em relação à resistência à compressão das peças, verificou-se que estatisticamente o resíduo de PVC influenciou na diminuição da resistência à compressão das peças, como observado nos estudos de Kaci et al. (2012) e Kou et al. (2009). 
Figura 6 - Micrografia obtida por MEV do concreto PVC0, PVC5, PVC10 e PVC15 com aproximação de 400 vezes

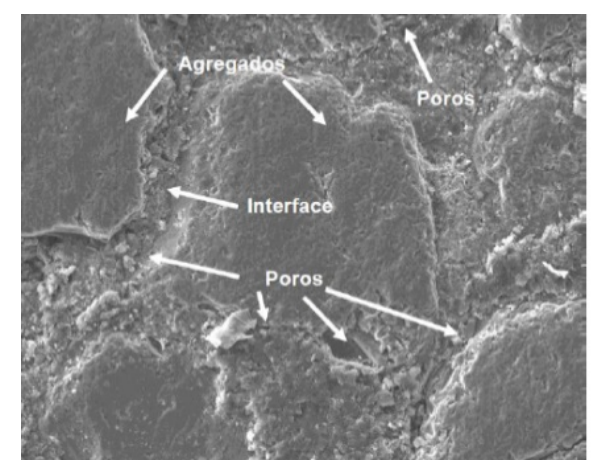

a) Traço de concreto - PVCO

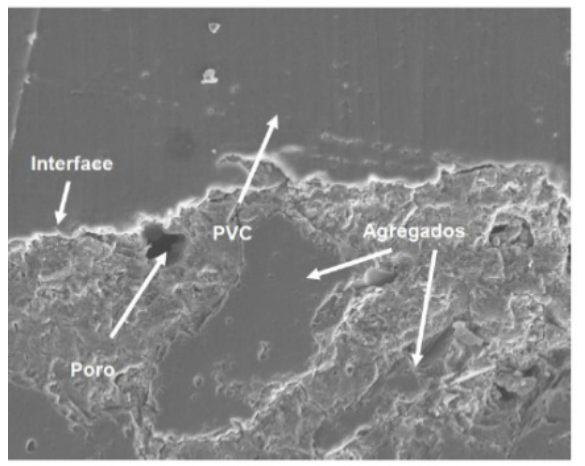

c) Traço de concreto - PVC10

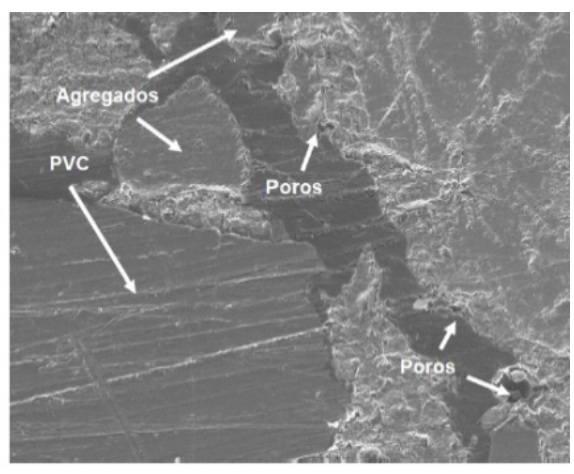

b) Traço de concreto - PVC5

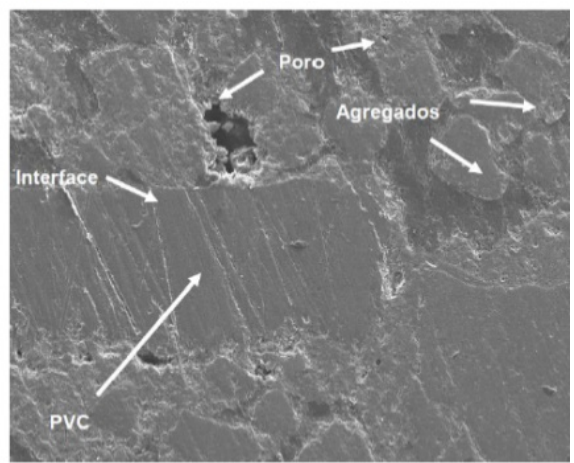

d) Traço de concreto - PVC15

Figura 7 - Micrografia obtida por MEV do concreto PVC10 com aproximação de 2.000 vezes

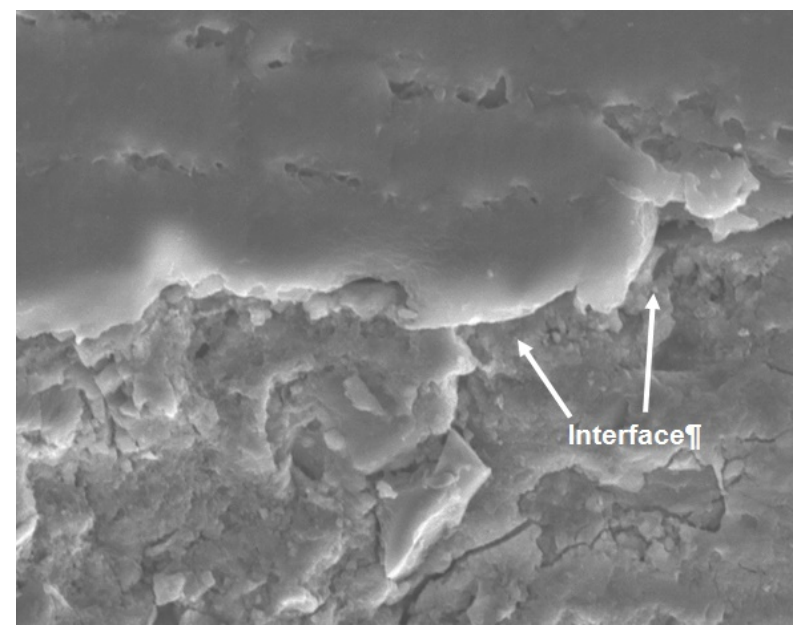

No ensaio de absorção de água verificou-se que estatisticamente o resíduo de PVC não influenciou nos resultados do ensaio nos traços avaliados. O traço PVC5 foi o que obteve maior média de absorção de água, como também o que obteve a menor resistência à compressão. A média do percentual de absorção de água dos traços avaliados ficou abaixo do limite exigido por norma, que é de $6 \%$.
Quanto ao índice de vazios das peças de concreto, verificou-se que estaticamente o resíduo de PVC não influenciou nos resultados. O valor da média do índice de vazios dos traços avaliados foi superior a $20 \%$, o que pode ser explicado pela existência de poros entre os agregados e a matriz cimentícia, observados na análise microscópica dos traços, mesmo após a compactação das peças.

No tocante ao ensaio de massa específica, pode-se verificar que estatisticamente o resíduo de PVC 
influenciou nos resultados do ensaio. O resíduo de PVC contribuiu para a diminuição da massa específica das peças de concreto. O traço com menor massa específica, ou seja, o mais leve foi o PVC10, enquanto o traço PVC0 foi o que apresentou a maior massa específica. Esse resultado pode ter ocorrido pelo fato de o PVC ter massa específica inferior ao agregado miúdo que foi substituído nas peças de concreto.

Quanto ao ensaio de durabilidade por secagem e molhagem, o traço que menos perdeu massa foi o PVC0. Pode-se observar o aumento da perda de massa com o aumento da porcentagem de PVC no traço do concreto.

Este estudo demonstrou que a utilização de resíduo de PVC moído como substituto parcial do agregado miúdo na fabricação de peças de pavimento intertravado pode ser considerada viável tecnicamente. Essa utilização também pode ser considerada ambientalmente viável, pois o PVC reciclado da forma mecânica produz menos poluição quando comparado aos outros processos de reciclagem. Sendo assim, contribui para preservação do ambiente e de seus recursos naturais, bem como no aumento da reciclagem de resíduos de construção e demolição. Como muitos resíduos são descartados sem que todo o seu potencial seja aproveitado, a reinserção dos materiais no ciclo da construção civil tem grande importância para o desenvolvimento sustentável.

\section{Referências}

ADEBOLA, A. A. et al. Utilization of Recycled Plastics (High Density Polyethylene) as Fine Aggregates in Construction. Journal of Experimental Research, v. 5, p. 17-21, 2017.

AGOPYAN, V.; JOHN, V. M. O Desafio da Sustentabilidade na Construção. São Paulo: Blucher, 2011.

ALWAELI, M. Application of Granulated LeadZinc Slag in Concrete as an Opportunity to Save Natural Resources. Radiation Physics and Chemistry, v. 83, p. 54-60, 2013.

AMADEI, I. B. A. Avaliação de Blocos de Concreto para Pavimentação Produzidos com Resíduos de Construção e Demolição do Município de Juranda/PR. 153 f. Maringá, 2011. Dissertação (Mestrado em Engenharia Urbana) Programa de Pós-Graduação em Engenharia Urbana, Universidade Estadual de Maringá, Maringá, 2011.

AMARAL, M. B. et al. Estudo para Utilização de Areia de Fundição em Blocos de Pavimentos Intertravados. Ijuí: Unijuí, 2013.
ASSOCIAÇÃO BRASILEIRA DE EMPRESAS DE LIMPEZA PÚBLICA E RESÍDUOS

ESPECIAIS. Panorama dos Resíduos Sólidos no

Brasil 2015. 2016. Disponível em:

<http://www.abrelpe.org.br/Panorama/panorama20 15.pdf> . Acesso em: 23 maio 2017.

ASSOCIAÇÃO BRASILEIRA DE NORMAS TÉCNICAS. ABNT NM 52: agregado miúdo: determinação da massa específica e massa específica aparente. Rio de Janeiro, 2009a.

\section{ASSOCIAÇÃO BRASILEIRA DE NORMAS}

TÉCNICAS. NBR 13554: solo cimento: ensaio de durabilidade por molhagem e secagem: método de ensaio, Rio de Janeiro, 2012.

\section{ASSOCIAÇÃO BRASILEIRA DE NORMAS}

TÉCNICAS. NBR 9778: argamassa e concreto endurecidos: determinação da absorção de água, índice de vazios e massa específica. Rio de Janeiro, 2009c.

\section{ASSOCIAÇÃO BRASILEIRA DE NORMAS}

TÉCNICAS. NBR 9781: peças de concreto para pavimentação: especificação e métodos de ensaio. Rio de Janeiro, 2013.

\section{ASSOCIAÇÃO BRASILEIRA DE NORMAS TÉCNICAS. NBR NM 248: agregados:} determinação da composição granulométrica. Rio de Janeiro, 2003.

\section{ASSOCIAÇÃO BRASILEIRA DE NORMAS} TÉCNICAS. NBR NM 53: agregado graúdo: determinação da massa específica, massa específica aparente e absorção de água. Rio de Janeiro, 2009b.

BITTENCOURT, S. F. Avaliação da Resistência à Compressão de Pavers Produzidos com Agregados de Resíduos de Construção e Demolição e Areia de Fundição. Limeira, 2012. Dissertação (Mestrado em Engenharia Civil) Escola de Engenharia, Universidade Estadual de Campinas, Limeira, 2012.

BUTTLER, A. M. Uso de Agregados Reciclados de Concreto em Blocos de Alvenaria Estrutural. São Carlos, 2007. Tese (Doutorado em Engenharia de Estruturas) - Pós-Graduação em Engenharia de Estruturas, Universidade de São Paulo, São Carlos, 2007.

\section{CARVALHO, E. V. Utilização do Resíduo da}

Retífica de Cerâmica de Revestimento na Produção de Concreto para Pavimento Intertravado. Limeira, 2013. 163 f. Dissertação (Mestrado em Tecnologia) - Faculdade de Tecnologia, Universidade Estadual de Campinas, Limeira, 2013. 
CHEN, C. et al. Environmental Impact of Cement Production: detail of the different processes and cement plant variability evaluation. Journal of Cleaner Production, v. 18, n. 5, p. 478-485, mar. 2010.

\section{CONFEDERAÇÃO NACIONAL DO}

TRANSPORTE. Transporte Rodoviário: por que os pavimentos das rodovias do Brasil não duram? Brasília: CNT, 2017.

COSTA, L. A. V. da; IGNÁCIO, R. P. Relações de Consumo x Meio Ambiente: em busca do Desenvolvimento Sustentável. Âmbito Jurídico, Rio Grande, v. 14, n. 95, dez. 2011.

DUTTA, S.; DAS, A. K. Analytical Perspective on Waste Management for Environmental Remediation. Revista TrAC Trends in Analytical Chemistry, v. 29, n. 7, p. 636-644, 2010.

FERREIRA, G. C. et al. Caracterização de Resíduos da Reciclagem de Postes de Concreto e Sua Utilização na Fabricação de Pisos Intertravados. In: CONGRESSO LUSOBRASILEIRO DE MATERIAIS DE CONSTRUÇÃO SUSTENTÁVEIS, 2., João Pessoa, 2016. Anais... João Pessoa, 2016.

GREGORIO, L. T. Orientações para Fabricação de Blocos de Concreto e Pisos Intertravados. PROJETO SHS Solução Habitacional Simples, Rio de Janeiro/Cachoeira Paulista, 2012.

HOOD, S. Análise da Viabilidade Técnica da Utilização de Resíduos de Construção e Demolição como Agregado Miúdo Reciclado na Confeç̧ão de Blocos de Concreto Para Pavimentação. Porto Alegre, 2006. Dissertação (Mestrado em Engenharia Civil) - Escola de Engenharia, Universidade Federal do Rio Grande do Sul, Porto Alegre, 2006.

INSTITUTO DO PVC. Brasil Recicla 19\% do Resíduo de PVC Pós-Consumo Gerado no País. 2013. Disponível em:

<http://www.institutodopvc.org/publico/?a=impren sa\&imp_id=236>. Acesso em: 23 out. 2015.

KACI, S. O. et al. Approche Expérimentale et Analytique du Béton Incorporant des Granulats en PVC. In: AUGC -IBPSA, 30., Chambery, 2012. Rencontres... Chambery, 2012.

KOU, S. C. et al. Properties of Lightweight Aggregate Concrete Prepared with PVC Granules Derived from Scraped PVC Pipes. Waste Management, v. 29, p. 621-628, 2009.
LIMA, A. C.; ROCHA, G. S.; KONAGANO, N. Y. H. A Utilização de Plásticos na Construção Civil. In: CONGRESSO BRASILEIRO DE EDUCAÇÃO EM ENGENHARIA, 40., Belém, 2012. Anais... Belém, 2012.

LOMASO, A. L. et al. Benefícios e Desafios na Implementação da Reciclagem: um estudo de caso no Centro Mineiro de Referência em Resíduos (CMRR). Revista Pensar Gestão e

Administração, v. 3, n. 2, jan. 2015.

MOURA, J. M. B. M. de et al. Placas Cimentícias e Pavers com Incorporação de Rejeitos da Coleta Seletiva do Município de Blumenau, SC.

Ambiente Construído, Porto Alegre, v. 18, n. 1, p. 345-359, jan./mar. 2018.

NABESHIMA, C. K. Y.; ORSOLIN, K.; SANTOS, R. K. X. Análise Comparativa Entre Sistemas de Pavimentação Urbana Baseados em Concreto Asfáltico e Blocos de Concreto Intertravados (Pavers). Curitiba, 2011. $122 \mathrm{f}$. Trabalho de Conclusão de Curso (Graduação em Engenharia de Produção Civil) - Curso Superior de Engenharia de Produção Civil, Universidade Tecnológica Federal do Paraná, Curitiba, 2011.

PORRERO, J. et al. Manual del Concreto Estructural. Caracas: Sidetur, 2004.

RAHMANI, E. et al. On the Mechanical Properties of Concrete Containing Waste PET Particles. Construction and Building Materials, Irã, v. 47, p. 1302-1308, 2013.

RODOLFO JUNIOR, A.; NUNES, L. R.; ORMANJI, W. Tecnologia do PVC. 2. ed., rev. e ampl. São Paulo: Pro, 2006.

SADAT-SHOJAI, M.; BAKHSHANDEH, G. R. Recycling of PVC Wastes. Polymer Degradation and Stability, p. 404-415, 2010.

SHARMA, R.; BANSAL, P. Use of Different Forms of Waste Plastic in Concrete: a review. Journal of Cleaner Production, v. 112, p. 473482, 2016.

SILVA, V. A.; FERNANDES, A. L. T. Cenário do Gerenciamento dos Resíduos da Construção e Demolição (RCD) em Uberaba-MG. Revista Sociedade \& Natureza, Uberlândia, v. 24, n. 2, p. 333-344, maio/ago. 2012.

TENNIS, P. D.; LEMING, M. L.; AKERS, D. J. Pervious Concrete Pavements. Illinois: Porland Cemente Association, 2004. 


\section{Adriana Goulart Santos}

Centro de Ciências Tecnológicas | Universidade do Estado de Santa Catarina | Campus Universitário Prof. Avelino Marcante, s/n, Bom Retiro | J oinville - SC - Brasil | CEP 89223-100 | Tel.: (47) 4009-7808 | E-mail: adriana.santos@udesc.br

\section{Ana Karoliny Ferrari}

Arquiteta | Rua Bento Gonçalves, 725, Glória | J oinville - SC - Brasil | CEP 89216-110 | Tel.: (47) 98402-9585 | E-mail: anakaroliny_3@hotmail.com

\section{Revista Ambiente Construído}

Associação Nacional de Tecnologia do Ambiente Construído

Av. Osvaldo Aranha, 99 - 3o andar, Centro

Porto Alegre - RS - Brasil

CEP 90035-190

Telefone: +55 (51) 3308-4084

Fax: +55 (51) 3308-4054

www. seer. ufrgs. br/ ambienteconstruido

E-mail: ambienteconstruido@ufrgs.br

(c) (i)

This is an open-access article distributed under the terms of the Creative Commons Attribution License. 